\title{
Prediction of stone-free status after single-session retrograde intrarenal surgery for renal stones
}

\author{
Şenol Tonyalı (1), Mehmet Yılmaz (D), Mustafa Karaaslan (D), Cavit Ceylan (1), Levent Işıkay (1)
}

Cite this article as: Tonyalı Ş, Yılmaz M, Karaaslan M, Ceylan C, Işıkay L. Prediction of stone-free status after single-session retrograde intrarenal surgery for renal stones. Turk J Urol 2018; 44(6): 473-7.

ORCID IDs of the authors: S.T. 0000-0003-1657-4044; M.Y. 0000-0003-3774-9982; M.K. 0000-0003-3453-3334; C.C. 0000-0001-5159-1291; L.I. 0000-0001-6345-0189.

Clinic of Urology, University of Health Sciences Türkiye Yüksek İtisas Training and Research Hospital, Ankara, Turkey

Submitted:

10.11.2017

Accepted:

26.03.2018

Available Online Date: 05.07.2018

Correspondence:

Senol Tonyalı

E-mail:

dr.senoltonyali@gmail.com

CCopyright 2018 by Turkish Association of Urology

Available online at www.turkishjournalofurology.com

\begin{abstract}
Objective: To determine the possible factors effecting stone-free status (SFS) after single-session retrograde intrarenal surgery (RIRS) for renal stones.

Material and methods: We retrospectively analyzed the charts of 100 consecutive patients who underwent RIRS. Unilateral procedures performed for single renal stones were included in the study. The studied parameters included patient demographics, stone characteristics (size, volume, location and attenuation according to Hounsfield unit [HU]), operation time, presence of preoperative double-J stent (DJS), use of ureteral access sheath (UAS) and SFS.

Results: The study population consisted of 100 patients where 43 of them were stone free and remaining 57 had residual stones. The mean age of the patients was $47.2 \pm 13.4$ years. The mean stone size (largest dimension), stone attenuation and stone volume were $14.8 \pm 5.8 \mathrm{~mm}, 1010 \pm 416 \mathrm{HU}$ and $937 \pm 929 \mathrm{~mm}^{3}$, respectively. The mean operative time was $60.8 \pm 24.2$ minutes. Mean stone size, volume and HU were higher in the RS group compared to SF group but without any statistically significant difference, $15.2 \pm 6.1 \mathrm{vs} .14 .2 \pm 5.3 \mathrm{~mm}$, $1056 \pm 1037 \mathrm{~mm}^{3}$ vs. $780 \pm 745 \mathrm{~mm}^{3}$ and $1061 \pm 374 \mathrm{HU}$ vs. $942 \pm 462 \mathrm{HU}$, respectively $(\mathrm{p}=0.490, \mathrm{p}=0.135$ and $\mathrm{p}=0.226$ ). In multivariate regression analysis stone location and UAS use were found to be the significant predictors of SFS. Patients with lower pole stones are 2.25 times likely to have residual stones after RIRS compared to patient's having stones at other localizations $(\mathrm{p}<0.001)$.
\end{abstract}

Conclusion: Stone volume could be a more reliable parameter than stone size in predicting RIRS success. Lower pole stone location and UAS use could be considered the most significant predictors of SFS after single session RIRS for single renal stones.

Keywords: Intrarenal surgery; nephrolithiasis; stone-free; stone location.

\section{Introduction}

Nephrolithiasis is a major health issue all around the world with a prevalence of $14.8 \%$ in Turkey. ${ }^{[1]}$ The management of nephrolithiasis has evolved during decades with the advances in technology and refinement of surgical tools. Renal stones historically treated with open surgery, nowadays usually managed by means of minimal invasive treatment modalities such as extracorporeal shock wave lithotripsy (ESWL), percutaneous nephrolithotripsy (PCNL), ureterorenoscopy (URS), retrograde intrarenal surgery (RIRS) and laparoscopic interventions. ${ }^{[2]}$

Retrograde intrarenal surgery using a flexible ureteroscope and laser has gained a broad popularity in recent years with advantages of being effective and having lower morbidity rates. ${ }^{[3]}$

Several studies have been made to determine the factors effecting stone-free status (SFS) and it has been tried to establish scoring systems predicting SFS after RIRS. ${ }^{[4-6]}$ However, there is a conflicting data in the literature and 
the most considered factors include stone number, size, volume, location and hardness of the stones, anatomical features eg. infundibulopelvic angle and experience of the surgeons. ${ }^{[7]}$

In the present study, we aimed to determine the possible factors effecting SFS after single-session RIRS for renal stones.

\section{Material and methods}

After obtaining institutional review board approval, we retrospectively analyzed the charts of 100 consecutive patients who underwent RIRS at our department between January 2014 and September 2017. The study was performed in accordance with the most recent version of the Declaration of Helsinki. Because of the retrospective nature of the study informed consent was not required. Unilateral procedures for single renal stones were included in the study. Patients who did not have a preoperative abdominal computed tomography (CT) or postoperative imaging were excluded from the study. Patients with anatomical abnormalities such as cross-renal ectopy, duplicated collecting system and pelvic kidney were also excluded. The studied parameters included patient demographics, stone characteristics [size, volume, location and hardness according to Hounsfield unit (HU)], operation time, presence of preoperatively inserted double-J stent (DJS), use of ureteral access sheath (UAS) and SFS. Stone volume was calculated using formula Length $\mathrm{x}$ Width $\mathrm{x}$ Height $\mathrm{x} \pi \mathrm{x}$ 0.167. Stone location was described in 2 subgroups: lower pole and non-lower pole. Patients were divided into two groups according to their SFS as stone-free (Group 1), and residual stone (RS) (Group 2) groups. The two groups were compared according to aforementioned variables.

\section{Surgical procedure}

All procedures were performed under general anesthesia using a 7.5 and 7.8 French (Flex-X2 ${ }^{\mathrm{TM}}$, Karl Storz, Germany and SemiFlex Scope ${ }^{\mathrm{TM}}$, MaxiFlex, USA) flexible ureteroscopes. Patients were placed on table in lithotomy position and draped. Fluoroscopic guidance of a mobile multidirectional C-arm fluoroscopy was used in all procedures. A 0.035 or 0.038 -inch guidewire was inserted into renal pelvis through ureter via a rigid ureteroscope. Then a $12 \mathrm{~F}$ UAS was passed over the guidewire up to the ureteropelvic junction (UPJ) under the guidance of C-arm scope. If it was not possible to insert a UAS, a $4.8 \mathrm{~F}$ or $6 \mathrm{~F}$ DJS was inserted into the ureter and the procedure was postponed for 3-4 weeks. According to the surgeon's preference some procedures were performed without UAS. A 270-micron holmium YAG laser was used to fragment the stone. Basket extraction of fragments was not used routinely and fragments left for spontaneous passage through the ureter. The decision of placing a DJS was made based on surgeon's preference related to procedure characteristics such as stone volume, mucosal rupture or ureteral injury. SFS was defined as absence of stones or any stones smaller than $2 \mathrm{~mm}$ on radiograms within a month after the procedure. Direct endoscopic vision at the time of RIRS or CT was used to determine the SFS of non-opaque renal stones.

\section{Statistical analyses}

Statistical analysis was performed using IBM Statistical Package for the Social Sciences Statistics for Mac v.21.0 (IBM SPSS Corp., Armonk, NY, USA). Quantitative values were shown as mean \pm SD for parametric data and median \pm range for nonparametric data. Qualitative values were shown as numbers and percentages. Normality test was performed using Shapiro-Wilk test. For the comparison of variables between SF and RS groups, Mann-Whitney U test and chi-square test were used. Multivariate regression analysis was used to evaluate the most significant predictor of SFS. The level of statistical significance was set at $\mathrm{p}<0.05$.

\section{Results}

In total, 149 procedures were reviewed. The analysis included 100 patients who met the inclusion criteria. Among 100 patients, 43 were stone free (SF-Group 1) and the remaining 57 had residual stones (RS-Group 2). The mean age of the patients was $47.2 \pm 13.4$ years. The study population consisted of 63 males and 37 females. The mean stone size (largest dimension), stone attenuation and stone volume were $14.8 \pm 5.8 \mathrm{~mm}, 1010 \pm 416 \mathrm{HU}$ and $937 \pm 929 \mathrm{~mm}^{3}$, respectively. The mean operative time was 60.8 24.2 [median 60 (95\% CI: (56-65.6) minutes. Preoperative DJS was placed in 22 patients. UAS was used in 76 procedures. 49 stones were left and 51 were right sided. Patient, stone and operation features are given in Table 1.

Mean stone size, volume and HU were higher in the RS group compared to SF group without statistically significant intergroup difference, $15.2 \pm 6.1$ vs. $14.2 \pm 5.3 \mathrm{~mm}, 1056 \pm 1037 \mathrm{~mm}^{3}$ vs. $780 \pm 745 \mathrm{~mm}^{3}$ and $1061 \pm 374 \mathrm{HU}$ vs. $942 \pm 462 \mathrm{HU}$, respectively $(\mathrm{p}=0.490, \mathrm{p}=0.135$ and $\mathrm{p}=0.226)$. Mean operation time was significantly longer in RS group compared to SF group, $65 \pm 24.7$ vs. 55.2 \pm 22.7 minutes $(\mathrm{p}=0.026)$. The SFR in lower pole stones was $22.2 \%$, which was significantly lower from the SFR $(60 \%)$ of other locations $(\mathrm{p}<0.001)$.

In multivariate regression analysis stone location and UAS use were found to be the significant predictors of SFS. Patients having lower pole stones were 2.25 times likely to have residual stones after RIRS compared to patients having stones at other localizations $(\mathrm{p}<0.001)$. SF rates in operations performed using UAS were 1.4 times higher than those realized without UAS $(\mathrm{p}=0.018)$. Stone volume also had a considerable impact on SFS however statistically significant intergroup difference was not detected $(\mathrm{p}=0.059)$. Stone laterality and preoperative DJ stenting found to have no impact on SFS ( $\mathrm{p}=0.486$ and $\mathrm{p}=0.679$, respectively). 
Table 1. Comparison of stone-free and residual stone groups

\begin{tabular}{|c|c|c|c|c|}
\hline \multicolumn{2}{|c|}{ Groups } & Stone-Free $(n=43)$ & Residual Stone (n=57) & $\mathbf{p}$ \\
\hline \multicolumn{2}{|c|}{ Mean stone size (mm) } & $14.2 \pm 5.3$ & $15.2 \pm 6.1$ & 0.490 \\
\hline \multicolumn{2}{|c|}{ Mean stone volume (mm3) } & $780 \pm 745$ & $1056 \pm 1037$ & 0.135 \\
\hline \multicolumn{2}{|c|}{ Mean stone attenuation (HU) } & $942 \pm 462$ & $1061 \pm 374$ & 0.226 \\
\hline \multirow[t]{2}{*}{ Side } & Right & $25(49 \%)$ & $26(51 \%)$ & 0.150 \\
\hline & Left & $18(36.7 \%)$ & $31(63.3 \%)$ & \\
\hline \multicolumn{2}{|c|}{ Mean operation time } & $55.2 \pm 22.7$ & $65 \pm 24.7$ & 0.026 \\
\hline \multicolumn{2}{|c|}{ Lower pole stone } & $10(22.2 \%)$ & $35(77.8 \%)$ & $<0.001$ \\
\hline \multicolumn{2}{|c|}{ Presence of preoperative DJS } & $9(40.9 \%)$ & $13(59.1 \%)$ & 0.501 \\
\hline \multicolumn{2}{|c|}{ Use of UAS } & $35(46.1 \%)$ & $41(53.9 \%)$ & 0.195 \\
\hline
\end{tabular}

\section{Discussion}

RIRS has gained popularity in recent years and is a widely accepted and used treatment modality in renal stone disease even in stones larger than $2 \mathrm{~cm}$ regardless of stone location..$^{[3,8]}$ With the advances in technology and refinement of flexible ureteroscope and laser fibers surgeons try to manage more complicated and larger renal stones by RIRS with lower morbidity to the patient. ${ }^{[3]}$

The main goal in performing stone surgery is to achieve a SFS. However, the reported SF rates (SFR) of RIRS in the literature varies between 54\%-96\% for renal stones smaller than $2 \mathrm{~cm}$ after one session and $86 \%-92 \%$ for renal stones larger than $2 \mathrm{~cm}$ after 1 to 4 sessions of RIRS ${ }^{[4]}$ In a study reporting single session RIRS outcomes in bilateral renal stones up to $15 \mathrm{~mm}$, the SFR was $86.8 \% .{ }^{[9]}$ This wide range emerges as a result of using different modalities (such as endoscopy, ultrasonography [US], plain radiograph or $\mathrm{CT}$ ) at different times after procedure to determine SFS. ${ }^{[4]}$ The definition of 'stone-free' also varies between studies. Studies utilizing modalities such as US or kidney-ureter-bladder radiography (KUB) might miss small fragments and overestimate the true SFR ${ }^{[8]}$ In our study, our average SFR was about $43 \%$ which was closer to the lower rates reported in the literature. This lower SFR rates might be due to reporting only single session results in our series and high mean stone volume. And also the residual stone size threshold for patients to be considered as having a stone free status was $2 \mathrm{~mm}$ in the present study which was also smaller than that accepted in some studies. ${ }^{[9]}$

Several studies have been conducted to determine the possible factors affecting SFR in RIRS, and various nomograms and scoring systems have been offered to predict SFR before RIRS. Size, volume, composition and location of the stone(s) in the kidney are the most studied parameters ${ }^{[5,10,11]}$ In a study, five independent predictors of SFS after RIRS were determined us- ing multivariate analysis consisted of stone volume, presence of lower pole stone, experience of the operator, number of stones and the presence of hydronephrosis. ${ }^{[11]}$

Stone size and/or volume have/has been reported to significantly affect SFR in RIRS. ${ }^{[12,13]}$ Goldberg et al. ${ }^{[12]}$ reported a significantly lower SFR (85\%) in renal stones $>15 \mathrm{~mm}$. The mean preoperative time, hospital stay and complication rate were also higher in patients with renal stones larger than $15 \mathrm{~mm}$. Thus, they suggested a stone size threshold of $15 \mathrm{~mm}$ to achieve higher SFR. However, in a systematic review RIRS has been found to be effective in renal stones larger than $2.5 \mathrm{~cm}$ and it has been suggested as an alternative to PCNL in selected patients. In that study, the overall SFR was $89.3 \%$ with an average of 1.6 procedures performed for each patient and the mean stone size was $2.9 \mathrm{~cm} \cdot{ }^{[3]}$ In the present study, stone volume was higher in patients with RS compared to SF patients and this difference was close to the level of statistical significance. Somehow any statistical significance was not observed related to the impact of stone volume on SFS in regression analysis which might be due to small number of patients in our study.

Location of the stone in renal collecting system is another extensively studied parameter effective on RIRS success. ${ }^{[14-17]}$ In a study by Jacquemet et al. ${ }^{[14]}$ stone size larger than $10 \mathrm{~mm}$ and multiple stone locations were found to be associated with RIRS failure. Moreover, they reported that location of stone in the lower pole had no impact on SFR. In concordance with Jacquemet et al. ${ }^{[14]}$, Martin et al. ${ }^{[15]}$ suggested that location stone in the lower pole had no impact on SFR. In that study, the SFR for lower pole stones was $74.1 \%$, which was not different from the SFR $(78 \%)$ of other locations $(\mathrm{p}=0.224)$. They concluded that location of stone in the lower pole might have an impact on SFR in case of presence of multiple stones and a history of PCNL. Similar to these studies Perlmutter et al. ${ }^{[17]}$ showed that stone location does not affect SFR in RIRS. They suggested RIRS as a 
safe and effective choice for lower pole stones up to $2 \mathrm{~cm}$ with a success rate greater than $90 \%$. In contrast with the aforementioned studies, some authors suggested lower pole stone location as a significant predictor of SFR before RIRS. ${ }^{[13,18]}$ In a study by Lim et al. ${ }^{[18]}$ SFR of RIRS in stones only in the lower pole was $73.3 \%$ which was lower than SFR of stones in upper pole, midpole or renal pelvis $(94.4 \%)$. Similarly, Ito et al. ${ }^{[13]}$ has found the presence of lower pole stone to be a predictive factor for SFS at RIRS. In a systematic review comparing the efficacy of RIRS, PCNL and ESWL in lower pole stones the SFR of RIRS was $91.7 \%$ in renal stones $\leq 20 \mathrm{~mm} \cdot{ }^{[19]}$ In the present study, location of stone in the lower pole was a significant predictor of SFS for single renal stones after single session RIRS. Thus, patients with a lower pole stone who desire to be SF after a single operation may be directed to alternative treatment modalities such as PCNL.

Stone attenuation measured as HU on non-contrast CT, is another parameter thought to affect SFR. In a study, while number of stones, presence of lower pole calculi, stone volume and diameter were significantly different between SF and non-SF patients; stone attenuation was not found to be a predictor of SFS. ${ }^{[20]}$ In our study, stone attenuation was found to have no impact on SFS

The use of a UAS, presence of preoperative DJS and use of ureteral stone basket for active removal of stones were also considered to affect SFR. ${ }^{[21-24]}$ However, it is difficult to come to a conclusion because of the various types of studies, patient and stone heterogeneity. In the present study, we observed the positive impact of use of UAS on SFS.

In conclusion, retrograde intrarenal surgery using flexible ureteroscope and laser fiber is a feasible treatment of choice for renal stones. Stone volume could be a more reliable parameter than stone size. Location of the stone in the lower pole stone could be considered the most significant predictor of SFS after single session RIRS for single renal stones. UAS use may help achieving SFS.

Ethics Committee Approval: Authors declared that the research was conducted in accordance with the principles of the World Medical Association Declaration of Helsinki "Ethical Principles for Medical Research Involving Human Subjects", (amended in October 2013).

Informed Consent: Given the retrospective nature of the study informed consent was not required.

Peer-review: Externally peer-reviewed.

Author Contributions: Concept - Ş.T., C.C.; Design - Ş.T., M.K., L.I.; Supervision - Ş.T., C.C., L.I.; Resources - M.K., M.Y.; Materials - Ş.T., C.C., L.I.; Data Collection and/or Processing - M.K., M.Y.; Analysis and/or Interpretation - Ş.T., C.C., L.I.; Literature Search -
Ş.T., M.Y., M.K.; Writing Manuscript - Ş.T.; Critical Review - Ş.T., M.K., M.Y., C.C., L.I.

Conflict of Interest: No conflict of interest was declared by the authors.

Financial Disclosure: The authors have declared that they didn't receive any financial support for their study.

\section{References}

1. Romero V, Akpinar H, Assimos DG. Kidney stones: a global picture of prevalence, incidence, and associated risk factors. Rev Urol 2010;12:e86-96.

2. Van Cleynenbreugel B, Kilic O, Akand M. Retrograde intrarenal surgery for renal stones -Part 1. Turk J Urol 2017;43:112-21. [CrossRef]

3. Breda A, Angerri O. Retrograde intrarenal surgery for kidney stones larger than $2.5 \mathrm{~cm}$. Curr Opin Urol 2014;24:179-83. [CrossRef]

4. Schoenthaler M, Wilhelm K, Katzenwadel A, Ardelt P, Wetterauer $\mathrm{U}$, Traxer $\mathrm{O}$, et al. Retrograde intrarenal surgery in treatment of nephrolithiasis: is a $100 \%$ stone-free rate achievable? J Endourol 2012;26:489-93.

5. Resorlu B, Unsal A, Gulec H, Oztuna D. A new scoring system for predicting stone-free rate after retrograde intrarenal surgery: the "resorlu-unsal stone score". Urology 2012;80:512-8.

6. Park J, Kang M, Jeong CW, Oh S, Lee JW, Lee SB, et al. External Validation and Evaluation of Reliability and Validity of the Modified Seoul National University Renal Stone Complexity Scoring System to Predict Stone-Free Status After Retrograde Intrarenal Surgery. J Endourol 2015;29:888-93. [CrossRef]

7. Sanguedolce F, Bozzini G, Chew B, Kallidonis P, de la Rosette J. The Evolving Role of Retrograde Intrarenal Surgery in the Treatment of Urolithiasis. Eur Urol Focus 2017;3:46-55. [CrossRef]

8. Ghani KR, Wolf JS, Jr. What is the stone-free rate following flexible ureteroscopy for kidney stones? Nat Rev Urol 2015;12:281-8.

9. Bansal P, Bansal N, Sehgal A, Singla S. Bilateral single-session retrograde intra-renal surgery: A safe option for renal stones up to $1.5 \mathrm{~cm}$. Urol Ann 2016;8:56-9. [CrossRef]

10. El Hamed AMA, Elmoghazy H, Aldahshoury M, Riad A, Mostafa M, Farag F, et al. Single session vs two sessions of flexible ureterosopy (FURS) for dusting of renal pelvic stones $2-3 \mathrm{~cm}$ in diameter: Does stone size or hardness play a role in number of sessions to be applied?. Turk J Urol 2017;43:158-61. [CrossRef]

11. Ito H, Sakamaki K, Kawahara T, Terao H, Yasuda K, Kuroda S, et al. Development and internal validation of a nomogram for predicting stone-free status after flexible ureteroscopy for renal stones. BJU Int 2015;115:446-51. [CrossRef]

12. Goldberg H, Golomb D, Shtabholtz Y, Tapiero S, Creiderman G, Shariv A, et al. The "old" $15 \mathrm{~mm}$ renal stone size limit for RIRS remains a clinically significant threshold size. World J Urol 2017;35:1947-54. [CrossRef]

13. Ito H, Kawahara $\mathrm{T}$, Terao H, Ogawa $\mathrm{T}$, Yao M, Kubota $\mathrm{Y}$, et al. The most reliable preoperative assessment of renal stone burden as a predictor of stone-free status after flexible ureteroscopy with 
holmium laser lithotripsy: a single-center experience. Urology 2012;80:524-8. [CrossRef]

14. Jacquemet B, Martin L, Pastori J, Bailly V, Guichard G, Bernardini S, et al. Comparison of the efficacy and morbidity of flexible ureterorenoscopy for lower pole stones compared with other renal locations. J Endourol 2014;28:1183-7. [CrossRef]

15. Martin F, Hoarau N, Lebdai S, Pichon T, Chautard D, Culty T, et al. Impact of lower pole calculi in patients undergoing retrograde intrarenal surgery. J Endourol 2014;28:141-5. [CrossRef]

16. Orywal AK, Knipper AS, Tiburtius C, Gross AJ, Netsch C. Temporal Trends and Treatment Outcomes of Flexible Ureteroscopy for Lower Pole Stones in a Tertiary Referral Stone Center. J Endourol 2015;29:1371-8. [CrossRef]

17. Perlmutter AE, Talug C, Tarry WF, Zaslau S, Mohseni H, Kandzari SJ. Impact of stone location on success rates of endoscopic lithotripsy for nephrolithiasis. Urology 2008;71:214-7. [CrossRef]

18. Lim SH, Jeong BC, Seo SI, Jeon SS, Han DH. Treatment outcomes of retrograde intrarenal surgery for renal stones and predictive factors of stone-free. Korean J Urol 2010;51:777-82. [CrossRef]

19. Donaldson JF, Lardas M, Scrimgeour D, Stewart F, MacLennan S, Lam TB, et al. Systematic review and meta-analysis of the clini- cal effectiveness of shock wave lithotripsy, retrograde intrarenal surgery, and percutaneous nephrolithotomy for lower-pole renal stones. Eur Urol 2015;67:612-6. [CrossRef]

20. Ito H, Kawahara T, Terao H, Ogawa T, Yao M, Kubota Y, et al. Predictive value of attenuation coefficients measured as Hounsfield units on noncontrast computed tomography during flexible ureteroscopy with holmium laser lithotripsy: a single-center experience. J Endourol 2012;26:1125-30. [CrossRef]

21. L'Esperance JO, Ekeruo WO, Scales CD, Jr., Marguet CG, Springhart WP, Maloney ME, et al. Effect of ureteral access sheath on stone-free rates in patients undergoing ureteroscopic management of renal calculi. Urology 2005;66:252-5. [CrossRef]

22. Zhang J, Xu C, He D, Lu Y, Hu H, Qin B, et al. Flexible ureteroscopy for renal stone without preoperative ureteral stenting shows good prognosis. Peer J 2016;4:e2728.

23. Shields JM, Bird VG, Graves R, Gomez-Marin O. Impact of preoperative ureteral stenting on outcome of ureteroscopic treatment for urinary lithiasis. J Urol 2009;182:2768-74. [CrossRef]

24. Kourambas J, Delvecchio FC, Munver R, Preminger GM. Nitinol stone retrieval-assisted ureteroscopic management of lower pole renal calculi. Urology 2000;56:935-9. [CrossRef] 